\title{
A very fast simulated annealing method for inversion of magnetic anomaly over semi-infinite vertical rod-type structure
}

\author{
$\operatorname{Arkoprovo~Biswas~}^{1}$ (D) Tapas Acharya $^{2}$
}

Received: 24 October 2016/Accepted: 2 November 2016/Published online: 11 November 2016

(C) Springer International Publishing Switzerland 2016

\begin{abstract}
A very fast simulated annealing (VFSA) global optimization method is used to interpret and modeling of magnetic anomaly over a vertically magnetized semi-infinite vertical rod-type structure. The results of VFSA optimization reveal that various parameters show a number of equivalent solutions when shape of the target body is unidentified and shape factor is also optimized together with other model parameters. The study reveals that restricting the shape factor to its actual value gives the utmost reliable results. Inversion of noise-free, noisy synthetic data and field data demonstrates the efficacy of the approach.
\end{abstract}

Keywords Magnetic anomaly - Semi-infinite vertical rod · VFSA · Uncertainty

\section{Introduction}

Geophysical surveys have been used to study an extensive range of geological structures. Those structures can be approximated by simple geological structures ranging in depth and size from deep basement blocks to near-surface ore bodies and has drawn significant attention in mineral exploration studies using various geophysical methods (Sharma et al. 2014; Biswas et al. 2014a, b; Biswas and Sharma 2016b). Out of various geophysical methods,

Arkoprovo Biswas

arkoprovo@gmail.com

1 Geophysics Group, Wadia Institute of Himalayan Geology, 33 GMS Road, Dehradun, Uttarakhand 248 001, India

2 Department of Geology, Hooghly Mohsin College, Chinsurah, West Bengal 712 101, India magnetic survey is also extensively applied in different exploration purposes (Mandal et al. 2013, 2015). Analyses of magnetic data are generally performed with the help of different interpretation techniques. The interpretation methods include curves matching (Gay 1963, 1965; McGrath 1970), Fourier transform (Bhattacharyya 1965), Hilbert transforms (Mohan et al. 1982), monograms (Prakasa Rao et al. 1986), least squares minimization (McGrath and Hood 1973; Silva 1989), characteristic points and distance approaches (Grant and West 1965; Abdelrahman 1994), correlation factors between successive least-squares residual anomalies (Abdelrahman and Sharafeldin 1996), Henkel transform (Singh et al. 2000), linearized least squares (Salem et al. 2004), normalized local wave number (Salem and Smith 2005), analytic signal derivatives (Salem 2005), Euler deconvolution (Salem and Ravat 2003), Fair function minimization (Tlas and Asfahani 2011a), deconvolution technique (Tlas and Asfahani 2011b), secondhorizontal derivatives (Abdelrahman and Essa 2015), Simplex algorithm (Tlas and Asfahani 2015). Also, simulated annealing (Gokturkler and Balkaya 2012), very fast simulated annealing (Sharma and Biswas 2013a; Biswas and Sharma 2014a, b, 2015; Biswas 2015), Particle swarm optimization (Singh and Biswas 2016) have been effectively used to solve similar nonlinear inversion problems of geometrically simple bodies.

The semi-infinite vertical rod-type structure was interpreted using Hankel Transform (Singh et al. 2000). However, no further development was made for interpretation of such kind of structure. In the current work, very fast simulated annealing (VFSA) is applied to determine the different model parameters related to semi-infinite vertical rod-type structure for magnetic anomaly. As, VFSA optimization is able to search a vast model space without negotiating the resolution and has the capacity to avoid 
becoming trapped in local minima (Sharma and Biswas 2011, 2013a, Biswas and Sharma 2015; Sharma 2012; Sen and Stoffa 2013; Biswas 2016a, b) and is used in interpreting the magnetic anomaly data. The applicability of the proposed technique is appraised and discussed with the help of synthetic noise-free, noisy data and one field example. This work is the first use of VFSA in interpreting magnetic anomaly over semi-infinite rod type structure.

\section{Theory and methodology}

\section{Theory}

The general expression of a magnetic anomaly $m(x)$ for semi-infinite vertical rod at any point on the surface (Fig. 1) is given by the equation (after Telford et al. 1990; Singh et al. 2000):

$m(x)=\left[\frac{I S \times z}{\left(x^{2}+z^{2}\right)^{q}}\right]$,

where, $I$ is the intensity of magnetization, $S$ is the cross sectional area of the rod, $z$ is the depth to the top of the rod, $x$ is the distance of the point of measurement and $q$ is the shape factor which is 1.5 .

\section{Inversion}

The Global optimization procedures such as simulated annealing, genetic algorithms, artificial neural networks and particle swarm optimization have been applied in

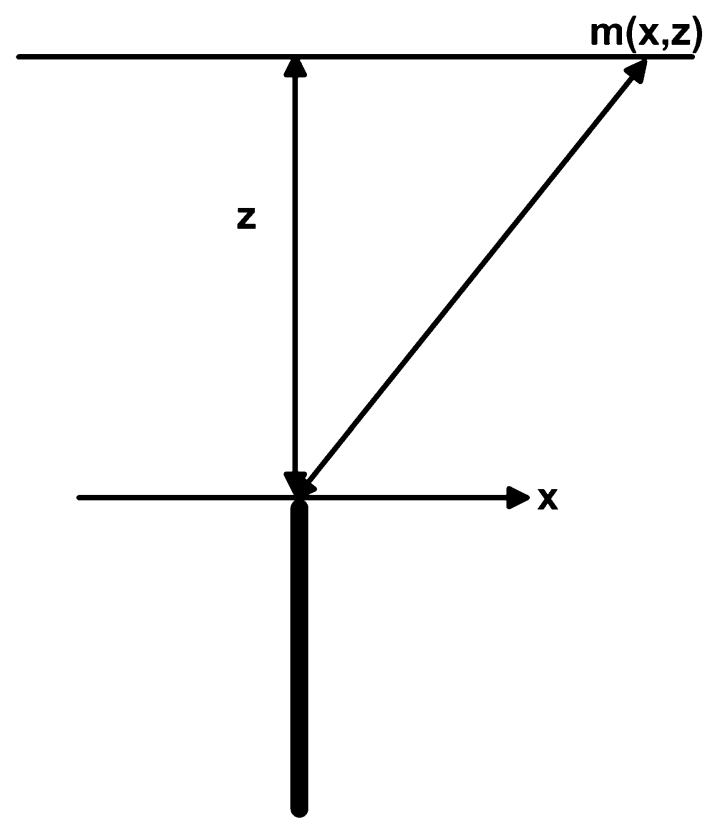

Fig. 1 A diagram showing cross-sectional views, geometries and parameters for semi-infinite vertical rod-type structure various geophysical data sets (Rothman 1985, 1986; Dosso and Oldenburg 1991; Zhao et al. 1996; Sharma and Kaikkonen 1998, 1999a, b; Juan et al. 2010; Sharma and Biswas 2011, 2013a, b; Sharma 2012; Sen and Stoffa 2013; Biswas and Sharma 2014a, b, 2015, 2016a; Biswas 2015, 2016a, b; Singh and Biswas 2016). In the present study, a variant of Simulated Annealig called as Very fast Simulated Annealing (VFSA) algorithm is developed. The details of Very Fast Simulated Annealing (VFSA) can be found in various literatures mentioned above. The following misfit $(\varphi)$ is used in the present study (after Sharma and Kaikkonen 1998; Biswas 2016a).

$\varphi=\frac{1}{\mathrm{~N}} \sum_{\mathrm{i}=1}^{\mathrm{N}}\left(\frac{\mathrm{V}_{\mathrm{i}}^{0}-\mathrm{V}_{\mathrm{i}}^{\mathrm{c}}}{\left|\mathrm{V}_{\mathrm{i}}^{0}\right|+\left(V_{\max }^{0}-V_{\min }^{0}\right) / 2}\right)^{2}$,

where $\mathrm{N}$ is number of data point, $V_{i}^{0}$ and $V_{i}^{c}$ are the $i$ th observed and model responses and $V_{\max }^{0}$ and $V_{\min }^{0}$ are the maximum and minimum values of the observed response, respectively.

The detailed VFSA algorithm can be found in the referred work of Sharma (2012); Sen and Stoffa (2013), Biswas (2013), Sharma and Biswas (2013a) and Biswas (2015).

A single run of global converging algorithm is not adequate to locate the global solution (Sen and Stoffa 2013). Henceforth, various great fitting models are streamlined (10 VFSA keeps running in the present study). Model parameters of these great fitting models may differ from each other and lie in a wide range in the multi-dimensional model space. It is important to test the models from the most reasonable zone (where countless are situated) of the model space. Diverse interpretation procedures have been utilized by various researchers (Mosegaard and Tarantola 1995; Sen and Stoffa 1996) to get the global model and minimize uncertainty in the solution. Examining in the model space depends on various statistical distributions and could contrast from one geophysical information to other. To obtain the best fittings model, parameters such as Initial temperature 1.0, cooling schedule 0.4 , number of iterations 2000 and number of moves per temperature 50 is used in the present study. Thus $10^{6}$ models and their misfits are stored in memory for subsequent statistical analysis. Further, selected models with higher misfit than a predefined threshold value $(0.0001$ for noise free synthetic data and 0.01/0.02 for noisy and field data) are ignored. Therefore, only models that fit the observed response up to a certain degree are selected for statistical analysis.

It is predictable that the histogram of model parameters of good-fitting models would follow a definite statistical distribution. Therefore, first, a histogram of all models that have misfit lower than the predefined threshold value is prepared to identify the appropriate statistical distribution. It has been observed during the present study that the 
Fig. 2 Flow chart of VFSA (after Sharma and Biswas 2013a)

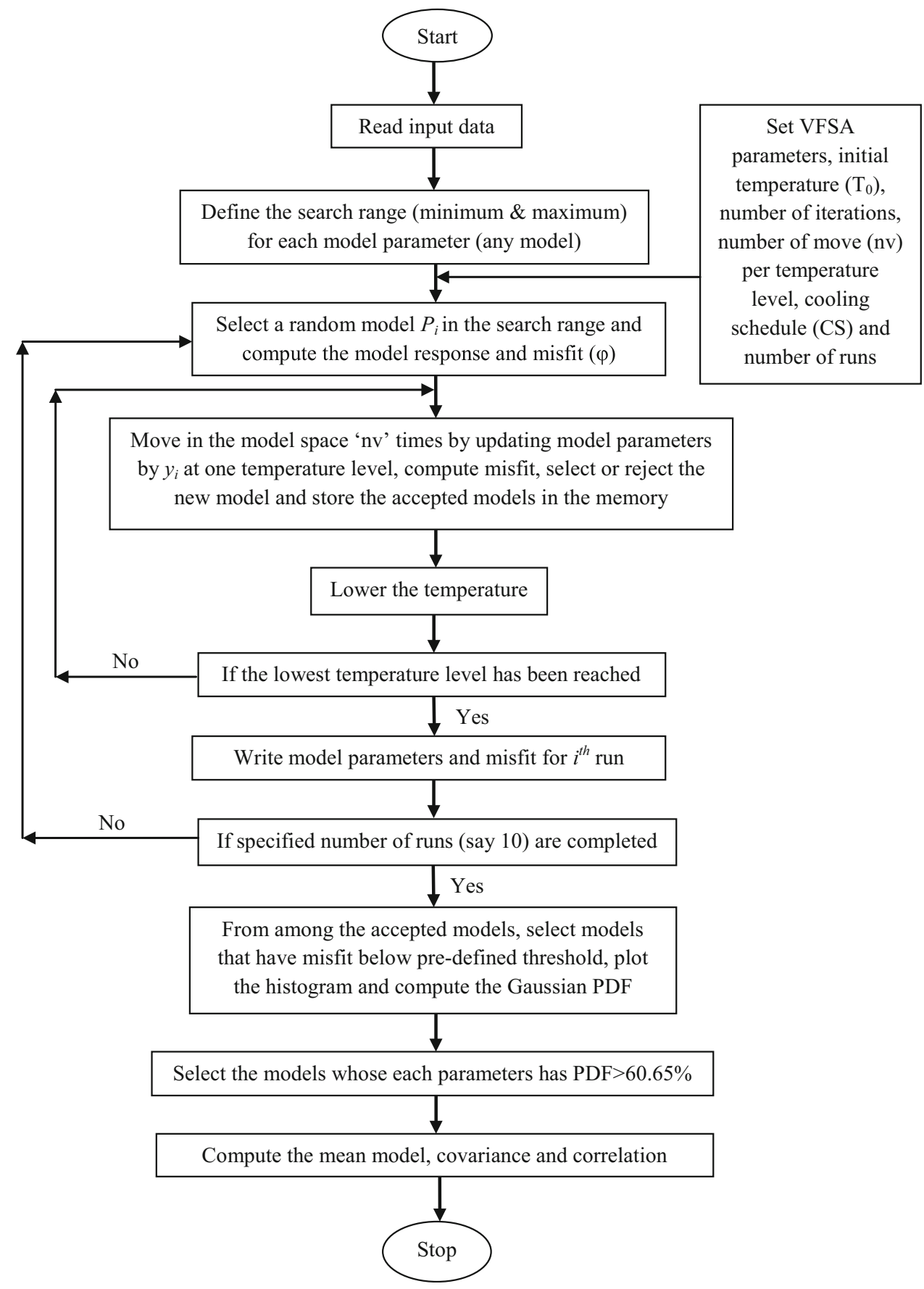

histogram of the models with misfit error smaller than the defined threshold shows a Gaussian distribution. Subsequently, Gaussian Probability Density Function (PDF) is computed using models that show misfit lower than the selected threshold value. The Gaussian probability density function $f_{y}\left(y, \mu, \sigma^{2}\right)$ of a variable $y$ is given by

$f\left(y, \mu, \sigma^{2}\right)=\frac{1}{\sigma \sqrt{2 \pi}} e^{-\frac{1}{2}\left(\frac{y-\mu}{\sigma}\right)^{2}}$.

In a Gaussian distribution, parameters denoted as $\mu$ and $\sigma$ is the mean and standard deviation, respectively, of the variable $y$. The PDF for all selected models is computed using Eq. (3) and subsequently the maximum value of PDF for each model parameter is chosen up. A $60.65 \%$ limit (one standard deviation) for the PDF is set for each parameter for the selection of good models lying in the high PDF region of the model space for the computation of the mean model. Any model, in which any parameter lies outside of one standard deviation, is also discarded. Thus models in the high probability region in the multidimensional model space are selected for computation of the mean model. The mean model is computed using the formulation given by Tarantola (2005). 
Table 1 Actual model parameters, search range and interpreted mean model for noise free and 10\% Gaussian noise data with uncertainty for Model 1

\begin{tabular}{|c|c|c|c|c|c|c|}
\hline \multirow{2}{*}{$\begin{array}{l}\text { Model } \\
\text { parameters }\end{array}$} & \multirow{2}{*}{$\begin{array}{l}\text { Actual } \\
\text { value }\end{array}$} & \multirow{2}{*}{$\begin{array}{l}\text { Search } \\
\text { range }\end{array}$} & \multicolumn{2}{|l|}{ Mean model (noise-free) } & \multicolumn{2}{|l|}{ Mean model (noisy) } \\
\hline & & & $q$ unrestricted & $q$ restricted & $q$ restricted & $q$ restricted \\
\hline $\begin{array}{l}\text { IS (amp- } \\
\text { turn-m) }\end{array}$ & $10^{6}$ & $10^{5}-10^{7}$ & $4,963,720.0 \pm 1,543,708.0$ & $1,006,186.0 \pm 18,397.6$ & $3,293,731.0 \pm 657,670.2$ & $1,050,313 \pm 229,367.6$ \\
\hline $\mathrm{x}(\mathrm{m})$ & 250 & $0-300$ & $250.0 \pm 0.7$ & $250.0 \pm 0.7$ & $251.95 \pm 7.5$ & $251.8 \pm 3.5$ \\
\hline $\mathrm{z}(\mathrm{m})$ & 1000 & $0-2000$ & $1035.1 \pm 11.8$ & $1002.9 \pm 9.0$ & $1021.9 \pm 103.5$ & $1012.9 \pm 35.9$ \\
\hline $\mathrm{q}$ & 1.5 & $0-2$ & $1.61 \pm 0.0$ & 1.5 (restricted) & $1.58 \pm 0.0$ & 1.5 (restricted) \\
\hline Misfit & & & $4.4 \times 10^{-3}$ & $2.2 \times 10^{-7}$ & $4.1 \times 10^{-4}$ & $1.9 \times 10^{-4}$ \\
\hline
\end{tabular}

The bold faces are to highlight the value of shape factor
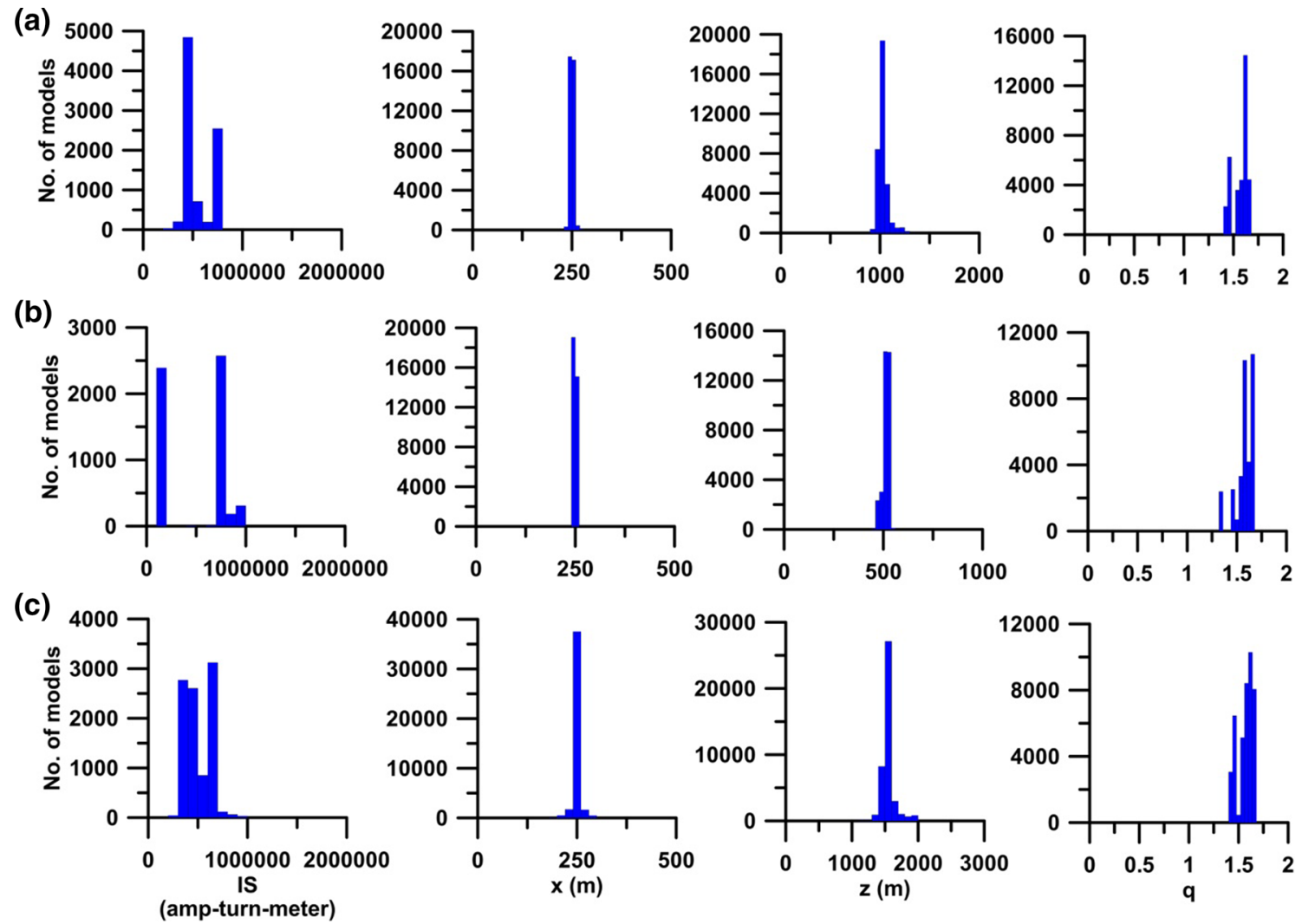

Fig. 3 Histograms of all accepted models having misfit $<10^{-4}$ for noise-free synthetic data when $q$ is unrestricted: a Model 1; b Model 2 and c Model 3

$$
\bar{P}_{i}=\frac{1}{N M} \sum_{n=1}^{N M} P_{i, n}
$$

In the above equation $N M$ is the number of models in a higher PDF region of the model space.

The code was developed using MS FORTRAN Developer studio in Window 7 environment on a simple desktop PC with Intel Pentium Processor. For each step of optimization, a total of $10^{6}$ forward computations (2000 iteration $\times 50$ number of moves $\times 10$ VFSA runs) were performed and accepted models stored in memory. A flowchart of the whole process is shown in Fig. 2.

\section{Results and discussion}

\section{Synthetic example}

The VFSA global optimization was applied using noisefree and noisy synthetic data (10\% and 20\% Gaussian 

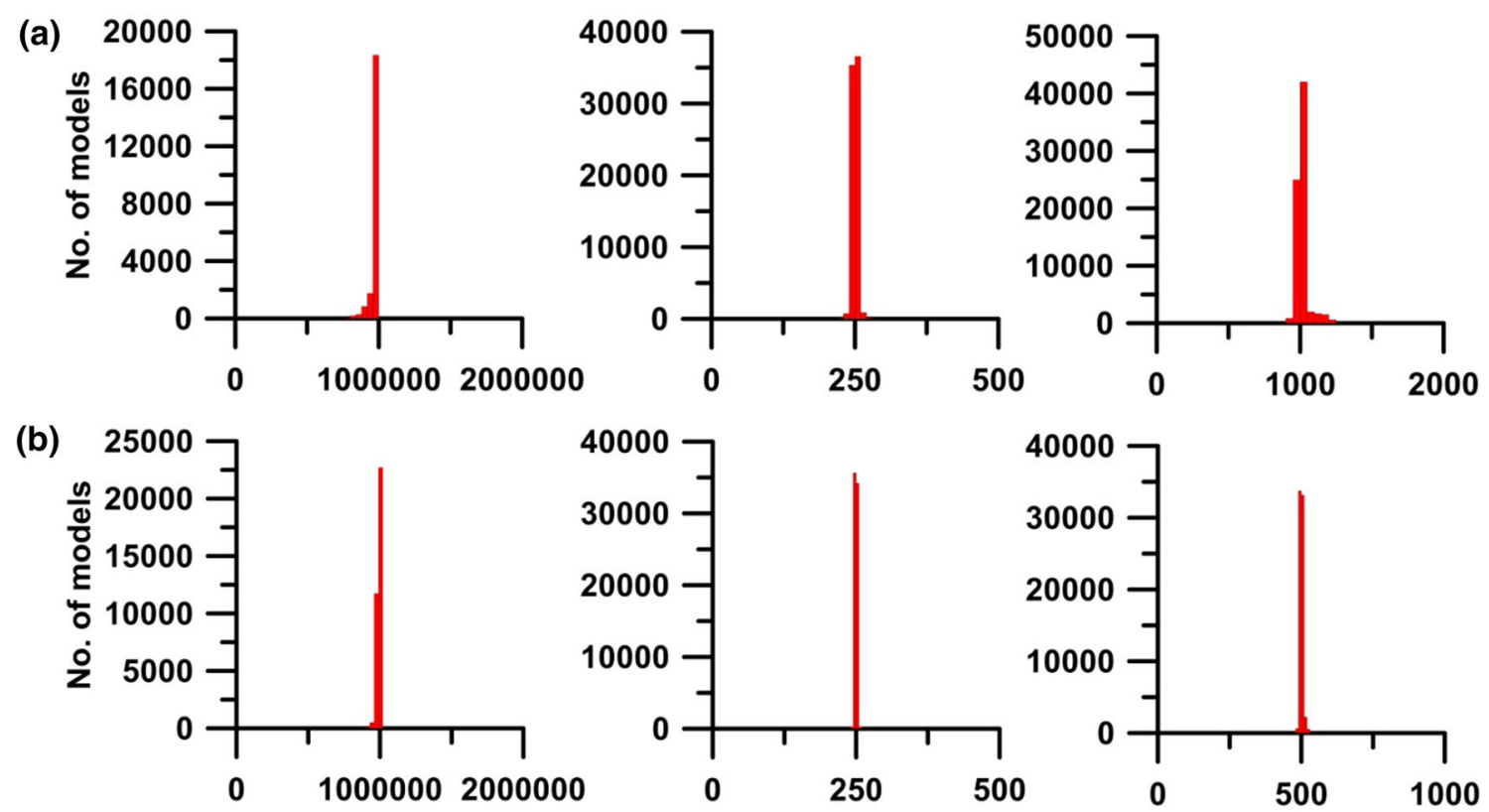

(c)
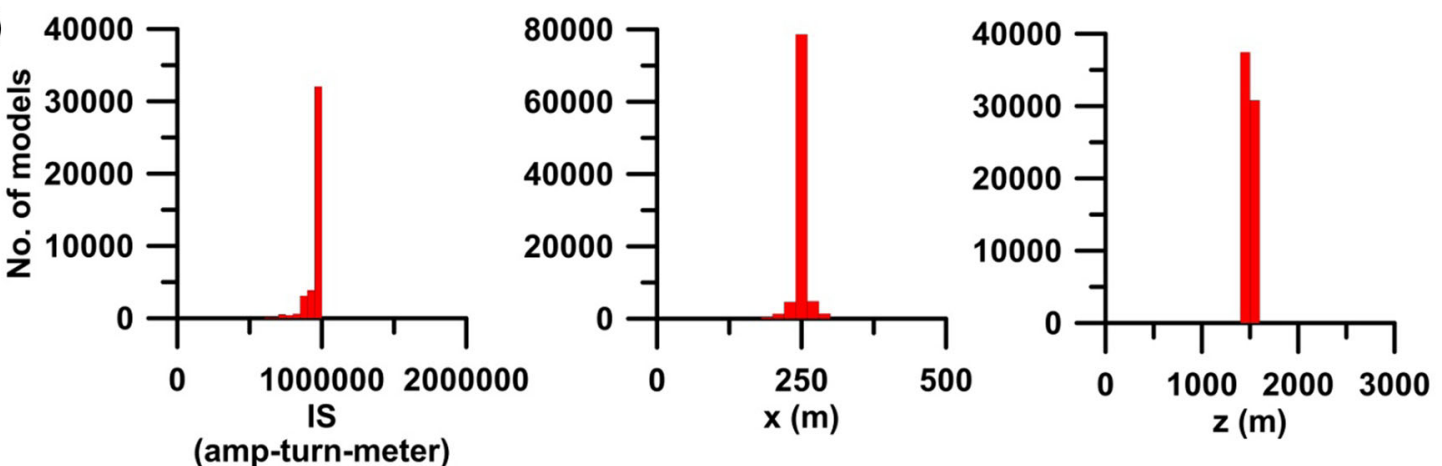

Fig. 4 Histograms of all accepted models having misfit $<10^{-4}$ for noise-free synthetic data when $q$ is restricted: a Model 1; b Model 2 and c Model 3

noise) for magnetic anomaly over a semi-infinite vertical rod-type model. Initially, all model parameters are optimized for each data set. The magnetic moment for each of the model has been chosen as $I S=10^{6}$ A-turn-meter.

\section{Model 1}

At first, synthetic data are generated using Eq. (1) for a semiinfinite vertical rod-type model (Table 1) and 10\% Gaussian noise was added to the synthetic data. Inversion was employed using noise-free and noisy synthetic data to retrieve the actual model parameters and study the effect of noise on the interpreted model parameters. Mainly, a suitable search range for each model parameter was selected and a single VFSA optimization was executed. After studying the proper convergence of each model parameter (IS, $x, z$, and $q$ ) and misfit by adjusting VFSA parameters (such as initial temperature, cooling schedule, number of moved per temperature and number of iterations), 10 VFSA runs were performed. Then, histograms (Fig. 3a) were prepared using accepted models whose misfit is lower than $10^{-4}$. The histograms in Fig. 3a depict that $x$ is closer to the actual solution however, other parameters such as $I S, z$ and $q$ shows an irregular distribution. A statistical mean model was computed using models that have misfit lower than $10^{-4}$ and lie within one standard deviation.

Table 1 depicts that the estimated mean model was far from the actual model and also it shows a large uncertainty (e.g. $I S)$. Other parameters $x, z$, and $q$ of the mean model were quite close to their actual values but actual model was not located within the estimated uncertainty. It divulges a strong relationship between different model parameters. This specifies that model parameters were inter-dependent and cannot be determined distinctively. Therefore, such kind of solution cannot be reliable and hence should not be used for the interpretation.

To avoid such undependable result, $q$ was restricted to its actual value at 1.5 and VFSA optimization was 

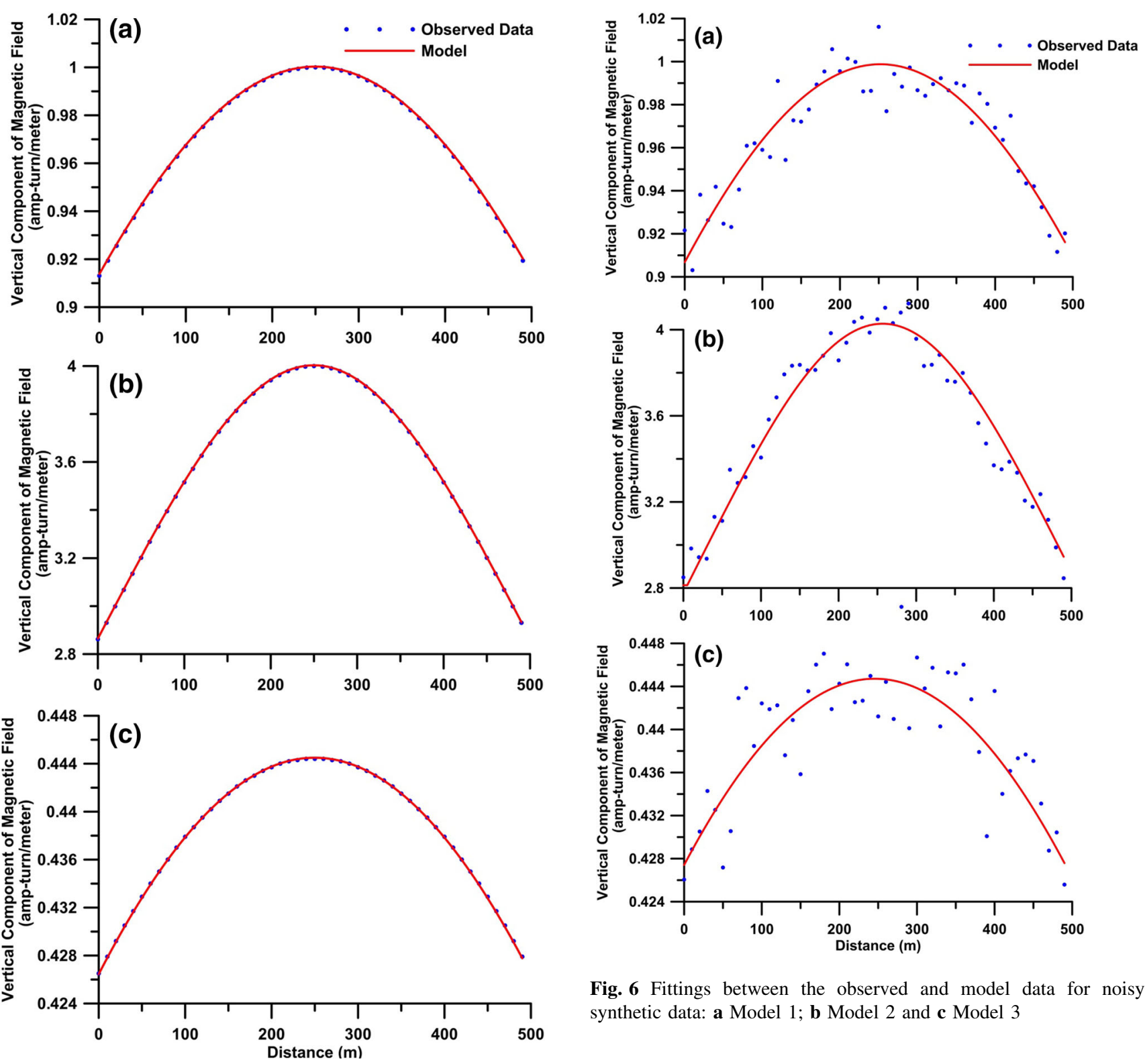

Fig. 6 Fittings between the observed and model data for noisy synthetic data: a Model 1; b Model 2 and c Model 3

Fig. 5 Fittings between the observed and model data for noise-free synthetic data: a Model 1; b Model 2 and $\mathbf{c}$ Model 3

Table 2 Actual model parameters, search range and interpreted mean model for noise free and 20\% Gaussian noise data with uncertainty for Model 2

\begin{tabular}{|c|c|c|c|c|c|c|}
\hline \multirow{2}{*}{$\begin{array}{l}\text { Model } \\
\text { parameters }\end{array}$} & \multirow{2}{*}{$\begin{array}{l}\text { Actual } \\
\text { value }\end{array}$} & \multirow{2}{*}{$\begin{array}{l}\text { Search } \\
\text { range }\end{array}$} & \multicolumn{2}{|l|}{ Mean model (noise-free) } & \multicolumn{2}{|l|}{ Mean model (noisy) } \\
\hline & & & $q$ unrestricted & $q$ restricted & $q$ unrestricted & $q$ restricted \\
\hline $\begin{array}{l}\text { IS (amp- } \\
\text { turn-m) }\end{array}$ & $10^{6}$ & $10^{5}-10^{7}$ & $3,864,848.0 \pm 1,717,070.0$ & $1,000,537.0 \pm 5507.2$ & $3,384,217.0 \pm 649,680.2$ & $944,787.6 \pm 259,467.3$ \\
\hline $\mathrm{x}(\mathrm{m})$ & 250 & $0-300$ & $249.9 \pm 0.3$ & $250.0 \pm 0.3$ & $251.9 \pm 3.5$ & $251.7 \pm 1.1$ \\
\hline $\mathrm{z}(\mathrm{m})$ & 500 & $0-1000$ & $517.2 \pm 6.0$ & $500.0 \pm 0.1$ & $483.9 \pm 10.5$ & $499.9 \pm 3.5$ \\
\hline $\mathrm{q}$ & 1.5 & $0-2$ & $1.59 \pm 0.0$ & 1.5 (restricted) & $1.59 \pm 0.0$ & 1.5 (restricted) \\
\hline Misfit & & & $8.4 \times 10^{-3}$ & $4.9 \times 10^{-7}$ & $4.4 \times 10^{-3}$ & $2.6 \times 10^{-4}$ \\
\hline
\end{tabular}

The bold faces are to highlight the value of shape factor 


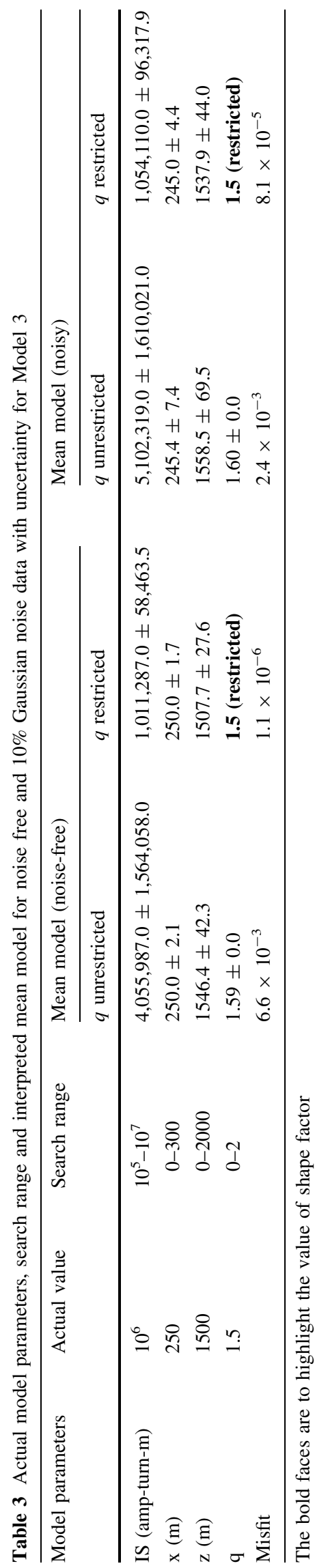

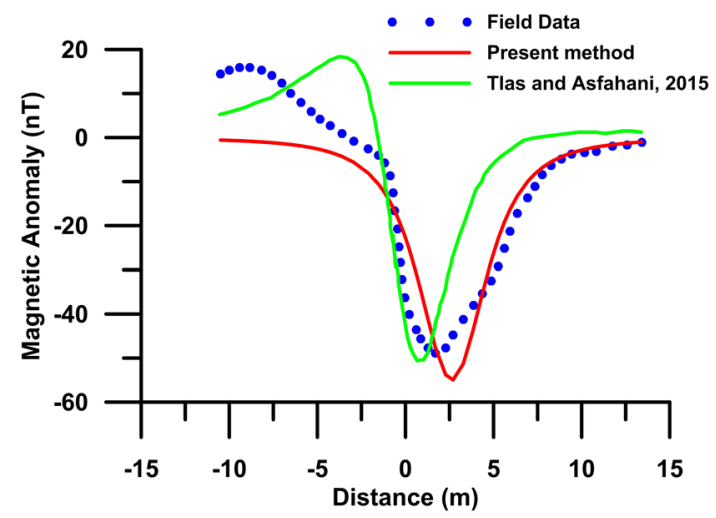

Fig. 7 Fittings between the observed and model data for Parnaiba Anomaly, Brazil

repeated again. The convergence of each model parameter $(I S, x, z$ and $q)$ and misfit was also studied. Figure $4 \mathrm{a}$ depicts the histogram of all accepted models with misfit less than $10^{-4}$. A statistical mean model was also computed using models that have misfit lower than $10^{-4}$ and lie within one standard deviation. Table 1 depicts that the estimated mean model and uncertainty. Figure 5a depicts a comparison between the observed and the mean model response.

Next, VFSA optimization was performed again using 10\% Gaussian noise added data for Model 1 (Table 1). The convergence of each model parameter and reduction of misfit was also studied for a single solution. After noticing the decrease of misfit systematically and stabilization of each model parameter during later iteration, ten VFSA runs were performed. The histogram shows similar nature like for noise-free synthetic data. A statistical mean model is also computed using models that have misfit lower than $10^{-2}$ and lie within one standard deviation. Table 1 depicts that the estimated mean model and uncertainty for noisy model. Figure 5a illustrates a comparison between the observed and the mean model response for noisy data.

\section{Model 2}

Another synthetic data were generated using Eq. (1) for a semi-infinite vertical rod-type model (Table 2) and 20\% Gaussian noise is added to the synthetic data to check the effect of more noise. Inversion is implemented using noisefree and noisy synthetic data to retrieve the actual model parameters and study the effect of higher noise on the interpreted model parameters. The procedure was repeated again as discussed in Model 1. The histogram is shown in Fig. $3 \mathrm{~b}$ when $q$ is unrestricted and Fig. $4 \mathrm{~b}$ when $q$ is restricted. Figures $5 \mathrm{~b}$ and $6 \mathrm{~b}$ show a comparison between the observed and the mean model response for noise-free and noisy data. 
Table 4 Search range and interpreted mean model for Parnaiba Anomaly, Brazil

\begin{tabular}{|c|c|c|c|c|c|c|}
\hline $\begin{array}{l}\text { Model } \\
\text { parameters }\end{array}$ & $\begin{array}{l}\text { Search } \\
\text { range }\end{array}$ & $\begin{array}{l}\text { Present method } \\
\text { (VFSA) }\end{array}$ & $\begin{array}{l}\text { Tlas and } \\
\text { Asfahani (2015) }\end{array}$ & $\begin{array}{l}\text { Abdelrahman and } \\
\text { Essa (2015) }\end{array}$ & $\begin{array}{l}\text { Asfahani and } \\
\text { Tlas (2007) }\end{array}$ & $\begin{array}{l}\text { Silva } \\
(1989)\end{array}$ \\
\hline IS (amp-turn-m) & -1000 to 0 & $-479.5 \pm 8.7$ & - & - & - & - \\
\hline $\mathrm{x}_{0}(\mathrm{~m})$ & -5 to 5 & $2.6 \pm 0.0$ & - & - & - & - \\
\hline $\mathrm{z}(\mathrm{m})$ & 0 to 10 & $2.9 \pm 0.0$ & 3.4 & 2.35 & 2.3 & 3.5 \\
\hline $\mathrm{q}$ & 1.5 & 1.5 & 2.0 & 1.02 & - & - \\
\hline Misfit & & $2.9 \times 10^{-2}$ & - & - & - & - \\
\hline
\end{tabular}

\section{Model 3}

Another synthetic data were generated using Eq. (1) for a semi-infinite vertical rod-type model (Table 3) and $10 \%$ Gaussian noise is added to the synthetic data. This model was taken to see the effect of higher depth and also to check the effect of noise. Inversion was also implemented the same way using noise-free and noisy synthetic data to retrieve the actual model parameters. The procedure was repeated again as discussed in Model 1. The histogram are shown in Fig. 3c ( $q$ unrestricted) and Fig. 4c ( $q$ restricted). Figures $5 \mathrm{c}$ and $6 \mathrm{c}$ demonstrate a comparison between the observed and the mean model response for noise-free and noisy data.

\section{Field example}

The field example is taken from Parnaiba basin, Brazil (after Silva 1989). The anomaly is associated with a Mesozoic diabase dike intruded into Paleozoic sediments (Fig. 7). The anomaly is obtained by digitizing at $0.4 \mathrm{~m}$ interval. This anomaly has been interpreted by several authors (Silva 1989; Asfahani and Tlas 2007; Abdelrahman and Essa 2015; Tlas and Asfahani 2015) assuming a horizontal cylinder and thin sheet model. The data is interpreted using VFSA technique. Table 4 presents the interpreted model parameters and uncertainty as well as comparison with other recently published results.

The depth of the body estimated in the present study is $2.9 \mathrm{~m}$. This depth is also matching with the other methods mentioned in the Table 4. However, the shape of the structure interpreted in the present study is vertical rod type structure which is closely matching with the thin sheet type structure. The present result however, matches well with the results of other methods and the results are in good agreement. A comparison between the field data and modeled data is shown in Fig. 7 and compared with Tlas and Asfahani 2015. It must be mentioned that the equation and the parameters are slightly different in case of present study but the important aspect is to find out the depth, shape and location of the body which is matching well with other interpretation methods.

\section{Conclusion}

The present work demonstrates the application of VFSA global optimization method for modeling and interpretation of magnetic anomalies over vertically magnetized semiinfinite vertical rod. Theoretical anomaly curves for three synthetic models are interpreted using VFSA approach for the model parameters: magnetic moment, location, depth and shape factor. The present study reveals that, while enhancing all model parameters together, the VFSA approach yields a number of equivalent solutions. It has been observed that the shape factor $q$ plays an important role in finding a steady appraisal of other model parameters. Hence, the inversion method was tested using two step procedures. In the first step, the shape factor was unrestricted and all model parameters were optimized. In the next step, the shape factor was restricted to its actual value and the model parameters were optimized. Thus, the most excellent reliable result has been obtained and uncertainty in the interpretation has also become of no importance. Interpreted results show significant match with those taken for the synthetic models. The efficacy of this approach has been successfully verified, recognized and authenticated using noise-free, noisy synthetic data as well as field data.

\section{References}

Abdelrahman EM (1994) A rapid approach to depth determination from magnetic anomalies due to simple geometrical bodies. J Univ Kuwait Sci 21:109-115

Abdelrahman EM, Essa KS (2015) A new method for depth and shape determinations from magnetic data. Pure Appl Geophys 172(2):439-460

Abdelrahman EM, Sharafeldin SM (1996) An iterative least-squares approach to depth determination from residual magnetic anomalies due to thin dikes. J Appl Geophys 34:213-220

Asfahani J, Tlas M (2007) A robust nonlinear inversion for the interpretation of magnetic anomalies caused by faults, thin dikes and spheres like structure using stochastic algorithms. Pure Appl Geophys 164:2023-2042

Bhattacharyya BK (1965) Two-dimensional harmonic analysis as a tool for magnetic interpretation. Geophysics 30:829-857

Biswas A (2013) Identification and resolution of ambiguities in interpretation of self-potential data: analysis and integrated study 
around South Purulia Shear Zone, India. Ph.D. thesis, Department of Geology and Geophysics, Indian Institute of Technology Kharagpur. doi:10.17.250.203:8080/xmlui/handle/123456789/ 3247

Biswas A (2015) Interpretation of residual gravity anomaly caused by a simple shaped body using very fast simulated annealing global optimization. Geosci Front 6(6):875-893

Biswas A (2016a) Interpretation of gravity and magnetic anomaly over thin sheet-type structure using very fast simulated annealing global optimization technique. Model Earth Syst Environ 2(1):30

Biswas A (2016b) A comparative performance of least square method and very fast simulated annealing global optimization method for interpretation of self-potential anomaly over 2-D inclined sheet type structure. J Geol Soc India 88(4):493-502

Biswas A, Sharma SP (2014a) Resolution of multiple sheet-type structures in self-potential measurement. J Earth Syst Sci 123(4):809-825

Biswas A, Sharma SP (2014b) Optimization of self-potential interpretation of 2-D inclined sheet-type structures based on very fast simulated annealing and analysis of ambiguity. J Appl Geophys 105:235-247

Biswas A, Sharma SP (2015) Interpretation of self-potential anomaly over idealized body and analysis of ambiguity using very fast simulated annealing global optimization. Near Surface Geophys 13(2):179-195

Biswas A, Sharma SP (2016a) Interpretation of self-potential anomaly over 2-D inclined thick sheet structures and analysis of uncertainty using very fast simulated annealing global optimization. Acta Geod Geophys. doi:10.1007/s40328-016-0176-2

Biswas A, Sharma SP (2016b) Integrated geophysical studies to elicit the structure associated with uranium mineralization around South Purulia Shear Zone, India: a review. Ore Geol Rev 72:1307-1326

Biswas A, Mandal A, Sharma SP, Mohanty WK (2014a) Delineation of subsurface structure using self-potential, gravity and resistivity surveys from South Purulia Shear Zone, India: implication to uranium mineralization. Interpretation 2(2):T103-T110

Biswas A, Mandal A, Sharma SP, Mohanty WK (2014b) Integrating apparent conductance in resistivity sounding to constrain 2D gravity modeling for subsurface structure associated with uranium mineralization across South Purulia Shear Zone. Int J Geophys 2014:1-8 (Article ID 691521)

Dosso SE, Oldenburg DW (1991) Magnetotelluric appraisal using simulated annealing. Geophys J Int 106:370-385

Gay SP (1963) Standard curves for the interpretation of magnetic anomalies over long tabular bodies. Geophysics 28:161-200

Gay SP (1965) Standard curves for the interpretation of magnetic anomalies over long horizontal cylinders. Geophysics 30:818-828

Gokturkler G, Balkaya C (2012) Inversion of self-potential anomalies caused by simple geometry bodies using global optimization algorithms. J Geophys Eng 9:498-507

Grant RS, West GF (1965) Interpretation theory in applied geophysics. McGraw-Hill Book Co, New York

Juan LFM, Esperanza G, José GPFÁ, Heidi AK, César OMP (2010) PSO: a powerful algorithm to solve geophysical inverse problems: application to a 1D-DC resistivity case. J Appl Geophys 71:13-25

Mandal A, Biswas A, Mittal S, Mohanty WK, Sharma SP, Sengupta D, Sen J, Bhatt AK (2013) Geophysical anomalies associated with uranium mineralization from Beldih mine, South Purulia Shear Zone, India. J Geol Soc India 82(6):601-606

Mandal A, Mohanty WK, Sharma SP, Biswas A, Sen J, Bhatt AK (2015) Geophysical signatures of uranium mineralization and its subsurface validation at Beldih, Purulia District, West Bengal, India: a case study. Geophys Prospect 63:713-724
McGrath H (1970) The dipping dike case: a computer curve-matching method of magnetic interpretation. Geophysics 35(5):831

McGrath PH, Hood PJ (1973) An automatic least-squares multi-model method for magnetic interpretation. Geophysics 38(2):349-358

Mohan NL, Sundararajan N, Seshagiri Rao SV (1982) Interpretation of some two-dimensional magnetic bodies using Hilbert transforms. Geophysics 46:376-387

Mosegaard K, Tarantola A (1995) Monte Carlo sampling of solutions to inverse problems. J Geophys Res 100(B7):12431-12447

Prakasa Rao TKS, Subrahmanyan M, Srikrishna Murthy A (1986) Nomograms for direct interpretation of magnetic anomalies due to long horizontal cylinders. Geophysics 51:2150-2159

Rothman DH (1985) Nonlinear inversion, statistical mechanics and residual statics estimation. Geophysics 50:2784-2796

Rothman DH (1986) Automatic estimation of large residual statics correction. Geophysics 51:337-346

Salem A (2005) Interpretation of magnetic data using analytic signal derivatives. Geophys Prospect 53:75-82

Salem A, Ravat D (2003) A combined analytic signal and Euler method (AN-EUL) for automatic interpretation of magnetic data. Geophysics 68(6): 1952-1961

Salem A, Smith R (2005) Depth and structural index from normalized local wavenumber of 2D magnetic anomalies. Geophys Prospect 53:83-89

Salem A, Ravat D, Martin FM, Ushijima K (2004) Linearized leastsquares method for interpretation of potential-field data from sources of simple geometry. Geophysics 69(3):783-788

Sen MK, Stoffa PL (1996) Bayesian inference, Gibbs sampler and uncertainty estimation in geophysical inversion. Geophys Prospect 44:313-350

Sen MK, Stoffa PL (2013) Global optimization methods in geophysical inversion, 2nd edn. Cambridge Publisher, London

Sharma SP (2012) VFSARES - a very fast simulated annealing FORTRAN program for interpretation of 1-D DC resistivity sounding data from various electrode array. Comput Geosci 42:177-188

Sharma SP, Biswas A (2011) Global nonlinear optimization for the estimation of static shift and interpretation of 1-D magnetotelluric sounding data. Ann Geophys 54(3):249-264

Sharma SP, Biswas A (2013a) Interpretation of self-potential anomaly over a $2 \mathrm{D}$ inclined structure using very fast simulated-annealing global optimization - an insight about ambiguity. Geophysics 78, WB3-15

Sharma SP, Biswas A (2013b) A practical solution in delineating thin conducting structures and suppression problem in direct current resistivity sounding. J Earth Syst Sci 122(4):1065-1080

Sharma SP, Biswas A, Mittal S, Sharma SP, Biswas A, Mittal S (2014) Delineation of extension of uranium mineralization zone using resistivity and very low frequency electromagnetic surveys around South Purulia shear zone, India. J Geol Soc India 84(6):645-656

Sharma SP, Kaikkonen P (1998) Two-dimensional nonlinear inversion of VLF-R data using simulated annealing. Geophys J Int 133:649-668

Sharma SP, Kaikkonen P (1999a) Appraisal of equivalence and suppression problems in 1-D EM and DC measurements using global optimization and joint inversion. Geophys Prospect 47:219-249

Sharma SP, Kaikkonen P (1999b) Global optimisation of time domain electromagnetic data using very fast simulated annealing. Pure Appl Geophys 155:149-168

Silva JBC (1989) Transformation of nonlinear problems into linear ones applied to the magnetic field of a two-dimensional prism. Geophysics 54:114-121

Singh A, Biswas A (2016) Application of global particle swarm optimization for inversion of residual gravity anomalies over 
geological bodies with idealized geometries. Nat Resour Res 25(3):297-314

Singh NP, Lal T, Banerjee M (2000) Application of Hankel transform in the interpretation of magnetic anomaly over semi-infinite vertical rod. Acta Geod Geophys Hungarica 35(2):143-148

Tarantola A (2005) inverse problem theory and methods for model parameter estimation, 1st edn. SIAM, Paris

Telford WM, Geldart LP, Sheriff RE (1990) Applied Geophysics, 2nd edn. Publication, Cambridge

Tlas M, Asfahani J (2011a) Fair function minimization for interpretation of magnetic anomalies due to thin dikes, spheres and faults. J Appl Geophys 75:237-243
Tlas M, Asfahani J (2011b) A new-best-estimate methodology for determining magnetic parameters related to field anomalies produced by buried thin dikes and horizontal cylinder-like structures. Pure Appl Geophys 168:861-870

Tlas M, Asfahani J (2015) The simplex algorithm for best-estimate of magnetic parameters related to simple geometric-shaped structures. Math Geosci 47(3):301-316

Zhao LS, Sen MK, Stoffa PL, Frohlich C (1996) Application of very fast simulated annealing to the determination of the crustal structure beneath tibet. Geophys Prospect 125:355-370 